\title{
FDA wants to invite women into drug trials earlier
}

Washington. In response to changing attitudes towards women, the US Food and Drug Administration (FDA) plans to loosen rules banning women of childbearing age from enrolling as subjects in the early tests of new drugs. The ban, which was prompted by fears that women in trials might get pregnant and bear deformed children, has been contested for several years by critics who say it violates women's civil rights. But even if FDA rescinds the ban, premenopausal women will probably continue to be ex-

\section{IMAGE UNAVAILABLE FOR COPYRIGHT REASONS}

\section{Many women want to be enrolled earlier.}

cluded from early trials because of fears by companies that they might be sued if a fetus were damaged by the experimental drug.

FDA's regulations, formalized in 1977, began as unofficial guidelines in the $1960 \mathrm{~s}$ after the thalidomide tragedy. The rules exclude women of childbearing age as subjects in drug trials until the drug concerned is known to be safe and effective. In practice, this rule eliminates women from phase I (toxicity) trials and the early part of phase II (small-scale efficacy) trials. Animal studies of the drug's effect on a fetus must also be completed before women enter trials. This provision effectively bars women from all but late phase II and phase III (large-scale efficacy) trials. The FDA does, however, waive these rules for drugs that could prolong or save lives.

There appear to be few compelling scientific reasons for including women in the earliest stages. Toxicity does not differ by gender; early enrolment would give investigators added time to work out the proper dosage and side effects in women, but the advantages are negligible. "There haven't been enough obvious [pharmacological] differences to make you think that women are different from men", says Leslie Benet of the school of pharmacy at the University of California, San Francisco.

The decision seems driven by political pressure and changing attitudes towards women. For the past several years, women within and outside FDA have complained that the ban is paternalistic and have urged the agency to allow women to choose their own level of risk exposure. The FDA is thought to apply a double standard; as evidence, women cite the recent trials for the prostate enlargement therapy Proscar, which at the time was thought to be a potential cause of birth defects. The trial's male subjects

were simply asked to use contraception and trusted not to father any children.

As legal suppor1 for their position, critics of the ban point to a unanimous decision last year by the US Supreme Court that female workers at a lead battery factory could not be barred from jobs exposing them to substances harmful to fetuses. As a result, "you need very good reasons to

keep women out", says Robert Temple of FDA's Center for Drug Evaluation and Research.

Having decided that the ban should be loosened, the FDA is developing rules giving women the choice to participate in early trials and protecting fetuses conceived by accident. Possible safeguards include a series of pregnancy tests during the trials and removing the ban only for drugs that leave the body too rapidly to affect a fetus. Some FDA officials favour revoking the ban altogether, as phase I trials consist of only a few dozen subjects taking a single dose of a drug.

No matter what FDA decides, concern that drug companies might be sued over a deformed fetus are likely to keep women of childbearing age out of early trials. Productliability lawyers agree that even a woman who has signed an informed consent form might win a liability suit if damage to the fetus were severe enough. A suit could also be filed by an adult subjected in utero to such tests. Some companies have suggested that they would enrol women earlier if Congress passed a law shielding them from liability, but the prospects of such a law are poor.
Traci Watson

\section{NASA researchers fear crackdown after security lapse}

Washington. Scientists at the National Aeronautics and Space Administration (NASA) Ames research centre in Mountain View, California, are concerned that academic freedoms may be restricted in the wake of an investigations by several federal agencies into a leak of secret computer codes and other abuses.

Last week, NASA issued a harshly worded press release blaming the "culture and environment" at Ames for a series of security breakdowns, some more than a year old. The scientists are "strongly biased towards maintaining an academic reputation, according to NASA, "rather than meeting US industry and national needs". As a result, NASA says that some aerospace companies are reluctant to share important data with NASA in case they are improperly disseminated. Daniel Goldin, the NASA administrator, called for a "culture change" at the laboratory, especially regarding contact with foreign researchers.

On the face of it, the NASA statement and a similar message given to Ames researchers at meetings last week imply that scientific and intellectual freedom at the laboratory may be curtailed. But those reading between the lines are playing down the impact on basic research. Most of the Ames scientists do applied work involving aerodynamic simulations and computer modelling, and the "security lapse" that triggered the investigation appears to have been a computer network leak of computer code for a hydrodynamic modelling algorithm. Those doing fundamental research - mostly in astronomy, cosmology and planetary studies - expect to continue interacting freely with outside colleagues.

The investigation involved some 30 NASA officials visiting the laboratory in August, locking researchers out of their offices while they looked for security leaks. Investigators found evidence of dozens of violations in security and procedures, ranging from an outside company operating within the laboratory to improper access to computers. The investigation appears to be part of a long-running conflict between Ames and NASA headquarters over the laboratory's independence rather than a response to a specific abuse.

Nevertheless, if NASA wants to bring Ames into line, life could become a good deal more difficult at the laboratory. Goldin has a reputation for forcing change and he may choose to make an example of Ames.

"A strong clampdown on exchanges does not bode well for our research mission", says Scott Sanford, an Ames physicist. "I hope the pendulum doesn't swing too far that way."

Christopher Anderson 